\title{
Tree invasions: patterns, processes, challenges and opportunities
}

\author{
David M. Richardson · Cang Hui • \\ Martin A. Nuñez • Aníbal Pauchard
}

Received: 1 October 2013/Accepted: 13 November 2013/Published online: 4 December 2013

(C) Springer Science+Business Media Dordrecht 2013

\begin{abstract}
Tree invasions have escalated in importance in the last few decades (more species, greater area invaded, more types of impacts, increasing complexity of management challenges), and are increasingly studied from many perspectives. This research spans many disciplines, including ecology, population biology, genetics, remote sensing, ecological modelling, risk analysis, resource economics and, increasingly, the humanities. There has been substantial progress in understanding patterns and processes, but many unanswered questions remain. Only a few invasive trees have been well studied, many of them in only a small part of their invasive range. Invasive trees often have substantial impacts, especially when they invade formerly treeless vegetation. Trees have several features that make them useful for understanding key aspects of biological invasions (the
\end{abstract}

D. M. Richardson $(\bowtie) \cdot$ C. Hui

Centre for Invasion Biology, Department of Botany and Zoology, Stellenbosch University, Private Bag X1,

Matieland 7602, South Africa

e-mail: rich@sun.ac.za

M. A. Nuñez

Laboratorio Ecotono, INIBIOMA, CONICET, University Nacional del Comahue, Quintral 1250, 8400 Bariloche, Argentina

A. Pauchard

Facultad de Ciencias Forestales, Institute of Ecology and Biodiversity (IEB), Universidad de Concepción,

Concepción, Chile determinants of invasiveness and invasibility), but also the full spectrum of human perceptions and values that frames biological invasions as an environmental problem. This editorial provides background and summarizes the main outputs from a workshop held in Argentina in September 2012 that set out to summarize current knowledge on key topics and to determine the most important challenges facing researchers and managers. The sixteen papers in the special issue of Biological Invasions span disciplines, geographic regions and taxa and provide novel insights on pathways and historical perspectives, detection and monitoring, determinants of invasiveness, function and impact, and the many challenges that face managers.

Keywords Introduction pathways - Impacts · Invasibility $\cdot$ Invasiveness $\cdot$ Tree invasions

\section{Introduction}

Trees did not feature prominently on national, regional and global lists of the most important invasive plants until fairly recently. In the past few decades, however, hundreds of tree species have become invasive (Richardson and Rejmánek 2011; Rejmánek and Richardson 2013), and many now feature on lists of the most widespread and damaging of all invasive species (Weber 2003; Richardson and Rejmánek 
Table 1 Major players contributing to knowledge of tree invasions

\begin{tabular}{lllll}
\hline Journals & Subject categories & Countries & Funding & Organizations \\
\hline Biol Invasions (198) & Environmental sciences/ecology (1,537) & USA (816) & NSF (110) & Stellenbosch U (45) \\
Plant Ecol (78) & Biodiversity conservation (484) & Australia (154) & USDA (26) & US Forest Service (44) \\
Biol Cons (58) & Plant sciences (195) & South Africa (89) & EU (18) & Rice U (41) \\
Divers Distrib (54) & Forestry (155) & Canada (85) & CIB (14) & US Geol Survey (38) \\
J Ecol (50) & Evolutionary biology (89) & France (76) & ARC (13) & U Florida (33) \\
Ecology (47) & Biochemistry molecular biology (61) & Germany (66) & ASCR (9) & Oregon State U (31) \\
Oecologia (46) & Physical geography (61) & New Zealand (62) & NSERC (9) & Colorado State U (30) \\
Rest Ecol (46) & Zoology (40) & Britain (60) & WfW (9) & U Cape Town (30) \\
Ecol Appl (42) & Genetics heredity (24) & Spain (51) & NC (8) & U Wisconsin (28) \\
J Appl Ecol (39) & Agriculture (20) & Japan (50) & CAS (7) & UC Davis (27)
\end{tabular}

The top 10 journals, ISI Web of Science subject categories, countries, funding agencies and organizations of the 1,537 publications in the Ecology category ( $>2,000)$ were listed from a search on Web of Science (5 November 2013) using 'tree*' and 'invasi*' as search terms. Numbers in brackets are the number of publications. NSF National Science Foundation, CIB DST-NRF Centre of Excellence for Invasion Biology, ARC Australian Research Council, ASCR Academy of Sciences of the Czech Republic, NSERC Natural Sciences and Engineering Research Council of Canada, WfW Working for Water Programme, South Africa, NC Nature Conservancy, $C A S$ Chinese Academy of Sciences. Some studies report on range expansions of native tree species within, or adjacent to the native range of the species

2011). Invasive trees have substantial and growing impacts on biodiversity, ecosystem functioning, and human livelihoods in many regions. However, many species are still useful, in some areas and in some contexts, for the same reasons for which they were introduced and disseminated, or for totally new uses. Few of the major invasive trees are exclusively desirable or undesirable; this creates complex, context-specific problems for researchers, society and managers.

The ultimate reason for the escalation of problems with tree invasions worldwide is the rapid increase in the human-mediated transport and dissemination of thousands of species for a wide range of purposes, especially forestry, agroforestry and ornamental horticulture. Vast plantations of alien trees now dominate many regions of the world. Alien trees are also increasingly conspicuous as ornamental and amenity plants and in different forms of agroforestry, and other species are widely used for food production. Largescale projects are championing the use of trees, mainly non-native species, for the provision of goods and services, especially in developing countries (Low 2012). The massive propagule pressure, in many cases coinciding with disturbances in receiving environments, is driving the emergence of invasions in many regions. The long time lag for tree invasions (Kowarik 1995) has probably given the false impression that trees are less invasive than some other plant forms, but the massive invasion debt created by a century or more of dissemination and planting of non-native trees is now leading to the manifestation of many large-scale invasions. Hundreds of papers now document diverse aspects of tree invasions (Table 1), including historical accounts of introductions and plantings, the emergence of problems with particular taxa and approaches for dealing with them, detailed studies on the ecology of invasions and the effects of invasive species, and the application of modern molecular techniques to reconstruct invasion histories and unravel fundamental aspects of their dynamics. The human dimensions of invasions have begun to be explored by historians, sociologists, philosophers and economists.

Despite the increasing attention to trees as invasive species worldwide, problems associated with these invasions are increasing in magnitude and complexity. There are very few success stories-where the extent and impacts of tree invasions have been reduced to the satisfaction of all stakeholders. Many introduced tree species are both crops of commercial, cultural or aesthetic importance in some parts of the landscape, but serious pests in others, creating vexing conflicts of interest which thwart or paralyse management efforts.

In September 2012 a workshop was held on Isla Victoria Island, Nahuel Huapi National Park near Bariloche, Argentina, to assess the state of knowledge of tree invasions worldwide. The meeting aimed to 
synthesize current knowledge in selected areas and to determine the most important challenges facing researchers and managers. The phenomenon of alien tree invasions was discussed and debated from many angles and perspectives during the 4-day meeting. The overall aim was to move the research agenda for tree invasions beyond the elucidation of case studies towards a more general understanding of the wide range of factors involved in mediating the outcome of introductions and shaping the options for management. The workshop was attended by 22 participants from at least nine countries (as reflected by their current affiliations) who brought diverse interests and experience with tree invasions.

This special issue of Biological Invasions comprises a collection of 16 papers that arose from deliberations at the workshop. The papers provide a reasonable cross-section and flavour of issues from the frontline of research on tree invasions. Early versions of all papers were presented and discussed at the meeting. All have undergone substantial revision and reworking based on discussions in Argentina and following peer review. This editorial provides a brief background to, and the rationale and context for, the special issue. It also summarizes the key findings of the papers and discusses some priorities for future work.

\section{Why study tree invasions?}

For several reasons, trees are particularly interesting subjects for the study of invasions. The natural experiment of tree introductions around the world (Richardson et al. 2004, 2011) provides many opportunities that have yet to be fully exploited to gain insights on the many interacting factors that mediate the outcome of introductions of different species. Several species have emerged as poster child examples of tree invasions; these include Melaleuca quinquenervia, Miconia calvescens, Mimosa pigra, Morella faya and Triadica sebifera (Richardson 2011). Various approaches, ranging from detailed autecological studies to macroecological or comparative studies have been undertaken to explore the drivers of invasions in a few key genera with many invasive species, notably Acacia (Richardson et al. 2011) and Pinus (Richardson 2006). In some cases, perspectives from these studies have been explicitly applied to other taxa. For example, life-history traits that confer invasiveness in Pinus (Rejmánek and Richardson 1996) and other conifers (Richardson and Rejmánek 2004) have been successfully used to predict invasiveness in woody plants in general (Rejmánek et al. 2013). However, much work remains to be done to test whether insights from model groups and systems can be reliably applied much more widely (Kueffer et al. 2013). Such insights are urgently required to improve our ability to screen species for invasiveness - both new introductions and species already widely planted and which may constitute a substantial "invasion debt" (sensu Essl et al. 2011).

Tree invasions into formerly treeless or tree-poor systems are relatively easy to detect and map, using conventional as well as new high-tech methods. This paves the way for obtaining data at levels of accuracy and at spatial scales that have hitherto been unavailable to population biologists and modellers for studying invasions over large areas. This, and advances in computer technology and the Internet, is opening new doors for the application of new analytical methods with the potential for shedding new light on the roles of many factors in mediating the success of introduced species at different stages of the introduction-naturalization-invasion continuum (Richardson and Pyšek 2012) and how they reshape invaded communities (Hui et al. 2013). Exciting advances in molecular ecology have revolutionized knowledge on the genetic structure of populations, allowing for the reconstruction of introduction and invasion histories (Le Roux et al. 2011), and shedding light on many aspects implicated in invasion dynamics, including the role of symbionts (Ndlovu et al. 2013). Many tree species are pioneer species and rapid colonizers in their native ranges, and some have become more abundant and/or undergone large range expansions in response to changing environmental factors. Such changes in abundance and distribution have been well studied and have shed light on many processes that are relevant for understanding range changes in novel environments (e.g. Richardson and Bond 1991 for Pinus; Polley et al. 2002 for Prosopis).

Trees have a special place in the human psyche, though the manifestation of this is highly context specific (e.g. Hayman 2003). In some contexts, wooded areas are perceived as being "good" (indicative of a healthy ecosystem) whereas treeless vegetation is perceived as "barren" or degraded. Such 
perceptions certainly drove tree-planting initiatives in the fynbos region of South Africa soon after European colonization (Richardson et al. 1997). In this region and in many others, the perception of trees has changed with the rise of conservation culture and invasive alien acacias, eucalypts, pines, and other species, are increasingly seem as undesirable by some sectors of society but as crucial resources by others (e.g. Kull et al. 2011). This duality has inevitably led to a lack of consensus about tree invasions, and in some cases to heated conflicts (Dickie et al. 2014).

Partly because of their large size, but also for other reasons, many trees are important ecosystem engineers. Adding trees to an ecosystem very often results in major changes, particularly in those systems that were previously treeless or poor in tree cover. Increased water use, changes to disturbance regimes, and diverse effects on local biodiversity have all been shown to result from alien tree invasions. Such impacts have led to substantial management programmes in many countries. Probably the most famous is the Working for Water program in South Africa which has since 1995 sought to reduce the major threat posed by alien tree invasions while simultaneously addressing key socio-political priorities relating to poverty alleviation (van Wilgen et al. 2011). In this case, the main justification for the major investment in management has been the indisputable impact of tree invasions on crucial ecosystem services-water production from catchments. Even in this case (van Wilgen and Richardson 2012), but much more so when the benefits of management are less closely tied to economically important resources, striking conflicts of interest have arisen that thwart or halt management interventions (e.g. Kull et al. 2011). Such problems call for a much better understanding and quantification of impacts of woody plant invasions and for objective approaches for unpacking elements of conflict and for finding solutions.

\section{Key insights from the special issue}

A word cloud constructed in Wordle (www.wordle. com) using the full text of all papers in the special issue (Fig. 1) reveals the many concepts and themes invoked in addressing the diverse issues covered in the 16 papers. Although influenced by the particular selection of studies featured in the special issue, the image provides a useful snapshot of the many dimensions that underpin a scientific understanding of the phenomenon of tree invasions and the issues that must be considered when considering management options. Emergent issues or focus areas that can be seen in the word cloud include the following:

Countries/regions South Africa, Australia, New Zealand [sustained introductions and wide-scale plantings in these countries has resulted in massive tree invasions], South America as a new hotspot of invasion? (Argentina, Chile, Brazil).

Genera: Acacia, Pinus, Eucalyptus, Casuarina [elements of invasiveness are well studied in the first two genera; eucalypts are interesting for their modest invasive success despite very wide dissemination; casuarinas have only recently been very widely planted and little is known of their invasion ecology].

Driving forces abundance, climate, forestry, planting, time, use [key factors that mediate tree invasions].

Processes establishment, dispersal, interactions, mutualisms, spread [indicating the diversity of mechanisms that need to be considered in tree invasions].

Scales global (world), regional, national, landscape, $\mathrm{x}$, (grid)cells, ecosystems, population, individuals, local, sites [integration of insights from different scales is needed to understand and manage tree invasions].

Research tools genetics, imagery (esp. Google Earth), metrics, models, traits [a sample of available methodologies used to study tree invasions].

Considerations for management abundance, benefits, change, conflict, control, costs, distribution, economic, effort, extent, habitat, impacts, novel(ty), range, removal, plantations, prediction, presence, risk, source, strategy, values [elements typically requiring elucidation in a multidimensional evaluation of issues relating to tree invasions].

Despite the variety of topics highlighted in the word cloud, some important areas of research relating to tree invasions did not receive strong attention in the special issue. The bias in favour of southern hemisphere case studies affects many issues, notably the attention given to species that are particularly problematic in this hemisphere. Despite this, the word cloud clearly shows a remarkable variety of topics of importance in the study of tree invasions. In the next section we discuss key findings from the special issue papers under five broad non-overlapping headings. 


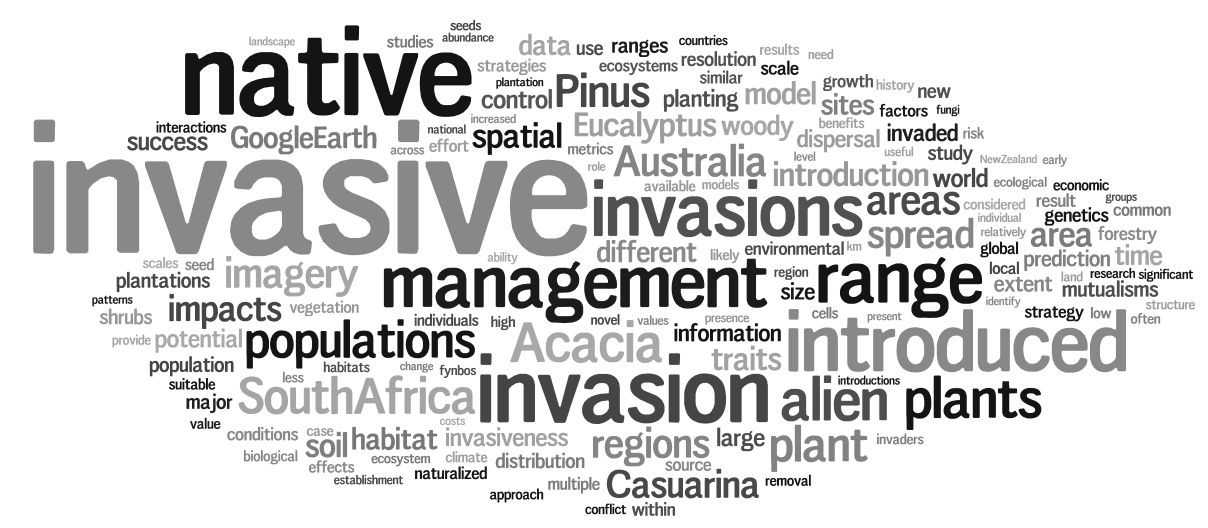

Fig. 1 Word cloud compiled from the full text (Abstract through Discussion) of the 16 papers in the special issue of Biological Invasions on "Tree invasions - patterns, processes, challenges and opportunities". References were excluded and the text was edited to remove author names and superfluous/ irrelevant words and to merge synonyms. The size of words is proportional to the number of times they appear
Fig. 2 The global donoracceptor network of invasive alien trees. Arrows indicate that a donor region has contributed more than five invasive species to an acceptor region [data from Table 3 in Rejmánek (2014)]. South America also includes Caribbean islands and Central America.

Regions on the outside of the figure play a minor role (or no role) as donors, whereas those towards the centre of the figure are major donors

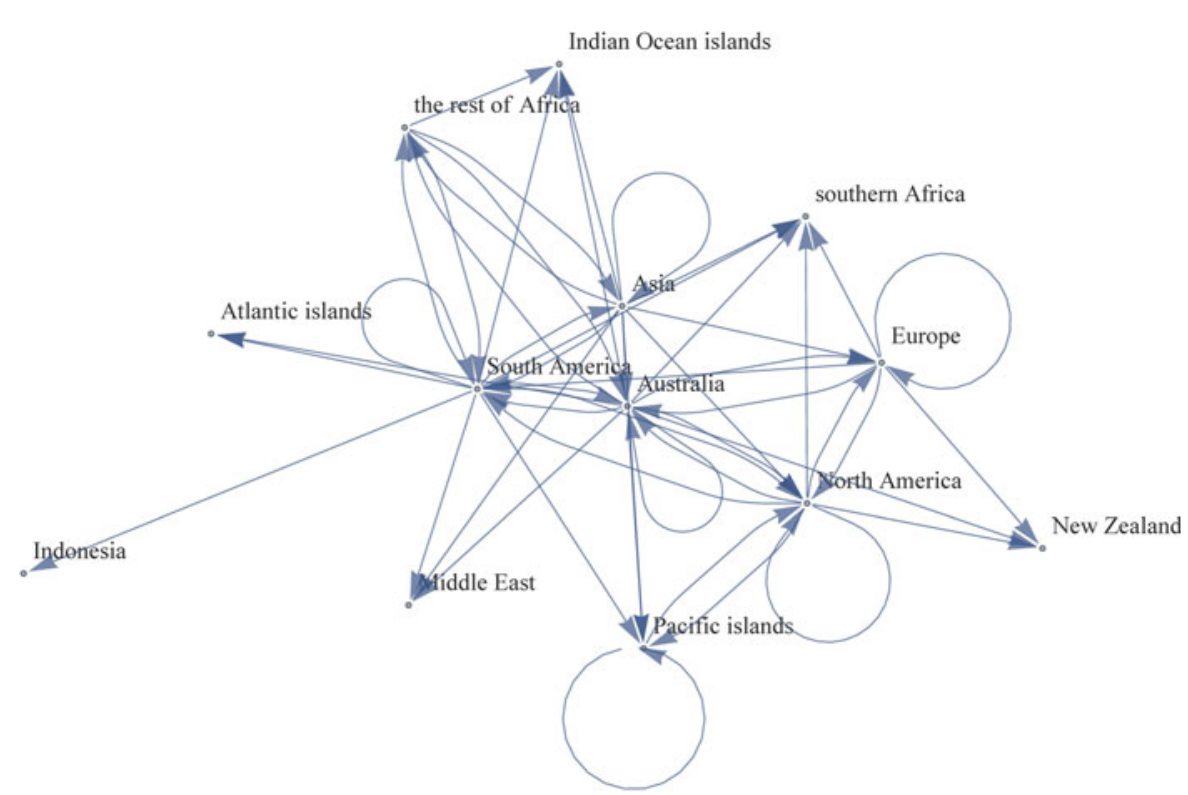

Pathways and history

Historical biases have defined the pathways for the global movement of tree species and how invasions have permeated perceptions of the environment in different parts of the world. Rejmánek (2014) provides a detailed analysis of the 434 trees known to be invasive in 15 regions of the world [using the list of species in Rejmánek and Richardson (2013)] to determine major trends in human-assisted exchanges of dendrofloras. Results of the analysis can be used to derive a donor-acceptor network of alien tree invasions (Fig. 2) which shows that some regions are much more important donors than others. This paves the way for further work to reconstruct invasion histories in different regions and explore and dissect apparent imbalances in the roles of some areas as acceptors and donors.

Bennett (2014) applies perspectives from environmental history to examine how invasions within a particular geographical, cultural, and ecological context (tree invasions in South African fynbos) were disproportionally important in shaping the awareness of invasions in other places. He argues that such "model invasions" have been valuable for catalysing national and international interest in biological 
invasion since the 1980s. This analysis suggests that much work remains to be done to unpack the rationale for particular ideologies in different regions. Such insights are crucial for developing sustainable management strategies.

\section{Detection and monitoring}

Because of their large size and since many tree invasions occur in formerly treeless vegetation, invasive trees are relatively easy to detect and map over large areas. Visser et al. (2014) assess the value of using freely available imagery on Google Earth to map invasions for research and management purposes. Despite some important limitations, this tool offers superb opportunities to gain insights on many aspects of tree invasions with obvious applications for research and management. Wilson et al. (2014) review the metrics most commonly used to measure tree invasions and propose a standardised set of metrics to streamline improved exchange of information among researchers and managers. Such standardised metrics are crucial for monitoring invasions, and for prioritizing and evaluating the efficacy of control methods. Focussing on Acacia invasions in South Africa, Donaldson et al. (2014) develop a protocol using scale-area curves for monitoring invasive tree distributions at different spatial scales. This approach is applied to explore the regional and national-scale distribution patterns for Acacia species introduced and disseminated for different purposes. Results show how distribution patterns at different spatial scales need to be considered when formulating comprehensive management plans.

\section{Determinants of invasiveness}

Understating why some species or populations are more invasive than others is a major challenge in invasion ecology. Five papers in the special issue address this broad topic in very different ways for trees. Hui et al. (2014) compared the native range structures of Australian eucalypts with those of Australian acacias. The human preference for introducing species with larger ranges was found to be much greater for acacias than for eucalypts as the native range of invasive acacias is three times larger than the range of invasive eucalypts, even though no difference was found in average range size for these two genera. The link between large range size and invasion success was only strong for acacias, not for eucalypts. These results are important for predicting trajectories of invasion success in these taxa. Pyšek et al. (2014) evaluated the global invasion success of temperate trees and shrubs with native ranges in central Europe. They explored the role of the native distribution of these species and of biological traits in determining whether they have become invasive elsewhere in the world. Their results also showed a strong effect of native range size, but emphasize the role of traits in conferring invasiveness. Gundale et al. (2014) propose Pinus contorta as a model species for studying how introduced tree species interact with local factors in their native and non-native ranges. They discuss requirements for a model taxon in this regard, and discuss options for deriving key insights on fundamental mediators of invasions from the study of $P$. contorta. Several species of Casuarina have been widely planted outside their native range. Although some species are already naturalized and invasive, many plantings are too recent for invasions to have occurred and it appears that a major invasion debt exists in many regions. Potgieter et al. (2014) provide a framework for assessing the invasion ecology of Casuarina taxa worldwide. They show that although some insights from widely-studied invasive trees apply to casuarinas, taxon-specific insights are crucial for understanding aspects of invasion and for guiding management. Zenni et al. (2014) argue that knowledge of the role of phenotypic plasticity and local adaption in determining invasiveness could improve the understanding of the performance of alien trees at different stages of the introduction-naturalization-invasion continuum and improve the ability to assess invasion risk. Results from all these studies have potential for incorporation into protocols for predicting invasiveness of introduced trees and guidelines for management.

Function and impact

Nuñez and Dickie (2014) studied the prevalence of coinvasions and novel associations of invasive trees and mutualistic soil biota (mycorrhizas and nitrogen-fixing bacteria). They found that many trees invade with their own symbionts rather than forming new associations in their invaded range. They also found that invasion of some mutualistic species, especially those with 
novel ecosystem functions, can have large impacts in native ecosystems. Rundel et al. (2014) explored why alien trees have been able to establish and proliferate so successfully in many ecosystems where native trees are either absent or rare. They propose a conceptual model of limiting factors and releases from these limitations for grassland and shrubland ecosystems. Such insights are important for understanding invasion dynamics and the profound impacts on ecosystem processes such as biogeochemical cycling, carbon sequestration and hydrology that such invasions cause. Both studies cast new light on the fundamental mediators of tree invasions.

\section{Management challenges}

Caplat et al. (2014) developed a spatially explicit model for prioritising and allocating management effort among management units in heterogeneous landscapes to slow or contain invasive trees. They show that targeting peripheral stands consistently yields the best results at the landscape scale, whereas the most efficient allocating of effort at the regional scale depends on both habitat quality and tree lifehistory. Kaplan et al. (2014) use the situation with emerging Acacia stricta invasions in South Africa to develop a protocol for objective risk mapping at multiple spatial scales and show how such insights are useful for assessing the feasibility of eradication. Dickie et al. (2014) discuss the dichotomy between positive and negative effects of invasive trees on ecosystem services and identify three areas where the conflicts over the removal of invasive trees are most likely to occur: urban and near-urban trees; trees that provide direct economic benefits; and invasive trees that are used by native species for habitat or food. Van Wilgen and Richardson (2014) review the evidence of tree invasion management. Focussing on experiences in South Africa, they argue for the implementation of a new approach to alien tree management involving multiple approaches to achieve sustainable outcomes.

\section{Priorities for future work}

Tree invasions are on the rise in many parts of the world-the number of invasive species is increasing, as is the area affected by invasions and the magnitude of impacts. Introductions and further plantings for plantation forestry, agroforestry and ornamentation are likely to continue, adding new species and increasing propagule pressure. Recent and ongoing plantings have committed many areas to new invasions in the future. These trajectories call for focussed work on several fronts to provide inputs to policies, strategies and management programme to deal with invasive alien trees.

Many papers in this special issue provide insights that are important for improving risk assessment protocols. Links between pathways of introduction and dissemination, life-history traits and environmental conditions provide information that can be used to enhance the accuracy of risk assessments. The very large number of invasive trees worldwide precludes detailed studies on each species. Gundale et al. (2014) and Potgieter et al. (2014) show that information from carefully selected model groups is useful, and further work in this direction is warranted (Kueffer et al. 2013). Taxon-specific information is, however, crucial in certain cases-e.g. where conflicts of interest exist-and detailed research on certain taxa and invasion events is required.

There is an urgent need for sharing of experiences between regions, including stories of successes, innovative approaches, and failures. Experiences with particular species in one part of the world are useful for predicting broad outcomes in other areas (e.g. Richardson et al. 2008; Wilson et al. 2011).

New uses for trees, such as biofuel production, are changing introduction pathways, with important implications for invasion risk. Lessons learnt from past invasions resulting from particular introduction histories (e.g. commercial forestry; Richardson and Blanchard 2011) and modelling approaches (e.g. Caplat et al. 2014; Donaldson et al. 2014) need to be applied to forecast the dimensions of problems from these new pathways to identify precautions that could reduce future problems.

In many parts of the world, society is starting to realize that tree introductions not only have benefits but also major costs and that tree invasions have detrimental effects on biodiversity and ecosystem services. However, much work remains to ensure that the threats posed by invasive trees are adequately contextualized to allow for rationale debate among multiple stakeholders to pave the way for pragmatic and sustainable solutions. Forestry certification 
schemes such as FSC (Forest Stewardship Council) now require that forestry companies include the negative externalities of tree planting invasions. This trend will likely increase in the future in response to stricter environmental regulations (see discussion in van Wilgen and Richardson 2014).

Prioritizing species and areas for management is becoming increasingly complex in all spheres of conservation given the many interacting problem and external factors. The situation regarding the management of invasive alien trees is no different. The fact that most of the most invasive species are commercially or otherwise important in some parts of the landscape but undesirable in others is a huge complicating factor. In some cases, solutions may lie in classic plant control using mechanical or chemical tools; in other cases solutions may be in the use of biological control using agents that reduce seed production and therefore the risk of invasive spread (the situation with Australian acacias in South Africa is probably the best example; Moran et al. 2005). In most cases, solutions will require transdisciplinary endeavours to find innovative approaches to conflict resolution. Approaches for multidimensional evaluation of perceptions of the problem and options for management are available (e.g. Schwartz et al. 2012) and need to be applied to problems relating to tree invasions. There is increasing interest and support for pragmatic solutions to invasions-e.g. the concept of novel ecosystems which calls for certain ecosystems to be managed without rigid application of native-alien or invasive-non-invasive criteria, but rather by considering clear objectives for ecosystem services and sustainability (Hobbs et al. 2013). However, a balance between nativeness and ecosystem function will have to be achieved. In areas where tree invasions have profoundly modified ecosystems and where restoration to some historical condition is either practically impossible or even undesirable, society may have to learn to live with invasive trees and the changes they have brought to ecosystems. In many other areas with lower levels of landscape transformation due or where the presence of the non-native species poses a clear threat to native biota and ecosystem services, control of the invaders may be achievable and desirable. Risk assessment at global and local scales should be required when adding new tree species to ecosystems or when expanding their plantings.
Acknowledgments We thank all participants in the tree invasions workshop on Isla Victoria Island for their contributions. DMR and $\mathrm{CH}$ acknowledge support from the DST-NRF Centre of Excellence for Invasion Biology and the National Research Foundation, South Africa (Grant 85417 to DMR; Grants 76912 and 81825 to $\mathrm{CH}$ ). $\mathrm{CH}$ acknowledges the support from the Elsevier Young Scientist Award. The Oppenheimer Memorial Trust supported the attendance of several participants. AP is funded by Fondecyt 1100792, ICM P05-002 and Conicyt PFB-23.

\section{References}

Bennett BM (2014) Model invasions and the development of national concerns over invasive introduced trees: insights from South African history. Biol Invasions 16. doi:10. 1007/s10530-013-0601-1

Caplat P, Hui C, Maxwell BD, Peltzer DA (2014) Cross-scale management strategies for optimal control of trees invading from source plantations. Biol Invasions 16. doi:10. 1007/s10530-013-0608-7

Dickie IA, Bennett BM, Burrows LE et al (2014) Conflicting values: ecosystem services and invasive tree management. Biol Invasions 16. doi:10.1007/s10530-013-0609-6

Donaldson JE, Richardson DM, Wilson JRU (2014) Scale-area curves: a tool for understanding the ecology and distribution of invasive tree species. Biol Invasions 16. doi:10. 1007/s10530-013-0602-0

Essl F et al (2011) Socioeconomic legacy yields an invasion debt. Proc Natl Acad Sci USA 108:203-207

Gundale MJ, Pauchard A, Langdon B, Peltzer DA, Maxwell BD, Nuñez MA (2014) Can model species be used to advance the field of invasion ecology? Biol Invasions 16. doi:10. 1007/s10530-013-0610-0

Hayman R (2003) Trees: woodlands and Western civilization. Hambledon, London

Hobbs RJ, Higgs ES, Hall CM (eds) (2013) Novel ecosystems: Intervening in the new ecological world order. WileyBlackwell, Oxford

Hui C, Richardson DM, Pyšek P, Le Roux JJ, Kučera T, Jarošík V (2013) Increasing functional modularity with residence time in the co-distribution of native and introduced vascular plants. Nat Commun 4:2454. doi:10.1038/ncomms3454

Hui C, Richardson DM, Visser V, Wilson JRU (2014) Macroecology meets invasion ecology: performance of Australian acacias and eucalypts around the world revealed by features of their native ranges. Biol Invasions 16. doi:10. 1007/s10530-013-0599-4

Kaplan H, van Niekerk A, Le Roux JJ, Richardson DM, Wilson JRU (2014) Incorporating risk mapping at multiple spatial scales into eradication management plans. Biol Invasions. doi:10.1007/s10530-013-0611-z

Kowarik I (1995) Time lags in biological invasions with regard to the success and failure of alien species. In: Pyšek P, Prach K, Rejmánek M, Wade M (eds) Plant invasions: general aspects and special problems. SPB Academic Publishers, Amsterdam, pp 15-38

Kueffer C, Pyšek P, Richardson DM (2013) Integrative invasion science: model systems, multi-site studies, focused metaanalysis, and invasion syndromes. New Phytol 200:615-633 
Kull CA, Shackleton CM, Cunningham PS et al (2011) Adoption, use, and perception of Australian acacias around the world. Divers Distrib 17:822-836

Le Roux JJ, Brown GK, Byrne M et al (2011) Phylogeographic consequences of different introduction histories of invasive Australian Acacia species and Paraserianthes lophantha (Fabaceae) in South Africa. Divers Distrib 17:861-871

Low T (2012) Australian acacias: weeds or useful trees? Biol Invasions 14:2217-2227

Moran VC, Hoffmann JH, Zimmermann HG (2005) Biological control of invasive alien plants in South Africa: necessity, circumspection, and success. Front Ecol Envirionm 3:71-77

Ndlovu J, Richardson DM, Wilson JRU, Le Roux JJ (2013) Coinvasion of South African ecosystems by an Australian legume and its rhizobial symbionts. J Biogeogr 40:1240-1251

Nuñez MA, Dickie IA (2014) Invasive belowground mutualists of woody plants. Biol Invasions. doi:10.1007/s10530-0130612-y

Polley HW, Johnson HB, Tischler CR (2002) Woody invasion of grasslands: evidence that $\mathrm{CO}_{2}$ enrichment indirectly promotes establishment of Prosopis glandulosa. Plant Ecol 164:85-94

Potgieter LJ, Richardson DM, Wilson JRU (2014) Casuarina: biogeography and ecology of an important tree genus in a changing world. Biol Invasions 16. doi:10.1007/s10530013-0613-X

Pyšek P, Jarošík V, Pergl J, Moravcová L, Chytrý M, Kühn I (2014) Temperate trees and shrubs as global invaders: the relationship between invasiveness and native distribution depends on biological traits. Biol Invasions 16. doi:10. 1007/s10530-013-0600-2

Rejmánek M (2014) Invasive trees and shrubs: where do they come from and what we should expect in the future? Biol Invasions 16. doi:10.1007/s10530-013-0603-z

Rejmánek M, Richardson DM (2013) Trees and shrubs as invasive alien species-2013 update of the global database. Divers Distrib 19:1093-1094. doi:10.1111/ddi.12075

Rejmánek M, Richardson DM (1996) What attributes make some plant species more invasive? Ecology 77:1655-1661

Rejmánek M, Richardson DM, Pyšek P (2013) Plant invasions and invasibility of plant communities. In: van der Maarel E, Franklin $\mathbf{J}$ (eds) Vegetation ecology, 2nd edn. WileyBlackwell, Oxford, pp 387-424

Richardson DM (2006) Pinus: a model group for unlocking the secrets of alien plant invasions? Preslia 78:375-388

Richardson DM (2011) Trees and shrubs. In: Simberloff D, Rejmánek M (eds) Encyclopedia of biological invasions. University of California Press, Berkeley, pp 670-677

Richardson DM, Blanchard R (2011) Learning from our mistakes: minimizing problems with invasive biofuel plants. Curr Opin Environm Sustain 3:36-42

Richardson DM, Bond WJ (1991) Determinants of plant distribution: evidence from pine invasions. Am Nat 137:639-668

Richardson DM, Pyšek P (2012) Naturalization of introduced plants: ecological drivers of biogeographic patterns. New Phytol 196:383-396
Richardson DM, Rejmánek M (2011) Trees and shrubs as invasive alien species-a global review. Divers Distrib 17:788-809. doi:10.1111/j.1472-4642.2011.00782.x

Richardson DM, Rejmánek M (2004) Invasive conifers: a global survey and predictive framework. Divers Distrib 10:321-331

Richardson DM, Macdonald IAW, Hoffmann JH, Henderson L (1997) Alien plant invasions. In: Cowling RM, Richardson DM, Pierce SM (eds) Vegetation of southern Africa. Cambridge University Press, Cambridge, pp 535-570

Richardson DM, Rouget M, Rejmánek M (2004) Using natural experiments in the study of alien tree invasions: opportunities and limitations. In: Gordon MS, Bartol SM (eds) Experimental approaches to conservation biology. University of California Press, Berkeley, pp 180-201

Richardson DM, van Wilgen BW, Nuñez M (2008) Alien conifer invasions in South America-short fuse burning? Biol Invasions 10:573-577

Richardson DM, Carruthers J, Hui C et al (2011) Humanmediated introductions of Australian acacias-a global experiment in biogeography. Divers Distrib 17:771-787

Rundel PW, Dickie IE, Richardson DM (2014) Tree invasions into treeless areas: mechanisms and ecosystem processes. Biol Invasions 16. doi:10.1007/s10530-013-0614-9

Schwartz MH, Hellmann JJ, McLachlan JM et al (2012) Integrating the scientific, regulatory and ethical challenges posed by managed relocation. Bioscience 62:732-743

Van Wilgen BW, Richardson DM (2012) Three centuries of managing introduced conifers in South Africa: benefits, impacts, changing perceptions and conflict resolution. J Environm Manage 106:56-68

Van Wilgen BW, Richardson DM (2014) Challenges and tradeoffs in the management of invasive alien trees. Biol Invasions 16. doi:10.1007/s10530-013-0615-8

Van Wilgen BW, Khan A, Marais C (2011) Changing perspectives on managing biological invasions: insights from South Africa and the working for water programme. In: Richardson DM (ed) Fifty years of invasion ecology. The legacy of Charles Elton. Wiley-Blackwell, Oxford, pp 377-393

Visser V, Langdon B, Pauchard A, Richardson DM (2014) Unlocking the potential of Google Earth as a tool in invasion science. Biol Invasions 16. doi:10.1007/s10530-013-0604-y

Weber E (2003) Invasive plant species of the world: a reference guide to environmental weeds. CAB International Publishing, Wallingford

Wilson JRU, Gairifo C, Gibson MR et al (2011) Risk assessment, eradication, and biological control: global efforts to limit Australian acacia invasions. Divers Distrib 17:1030-1046

Wilson JRU, Caplat P, Dickie IA et al (2014) A standardized set of metrics to assess and monitor tree invasions. Biol Invasions 16. doi:10.1007/s10530-013-0605-x

Zenni RD, Lamy J-B, Lamarque JL, Porté AJ (2014) Adaptive evolution and phenotypic plasticity during naturalization and spread of invasive species: implications for tree invasion biology Biol Invasions 16. doi:10.1007/s10530-0130607-8 